\title{
NEW ADVANCES IN POST-INSTALLED SUBSEA MONITORING SYSTEMS FOR STRUCTURAL AND FLOW ASSURANCE EVALUATION
}

\author{
Reza Asgharzadeh Shishavan \\ Brigham Young University \\ 350 Clyde Building \\ Provo, Utah, 84602 \\ Email: reza_asghar_sh@byu.edu \\ John D. Hedengren \\ Brigham Young University \\ 350 Clyde Building \\ Provo, Utah, 84602 \\ Email: john.hedengren@byu.edu
}

\author{
David V. Brower \\ Astro Technology, Inc. \\ 712 Main Street, Suite 3200 \\ Houston, Texas 77002 \\ Email: dbrower@astrotechnology.com
}

\author{
Alexis D. Brower \\ Astro Technology, Inc. \\ 712 Main Street, Suite 3200 \\ Houston, Texas 77002 \\ Email: abrower@astrotechnology.com
}

\section{ABSTRACT}

An overview of fiber optic sensors for temperature, pressure, strain, and fatigue of subsea structures is provided. Current progress details efforts to ensure proper installation and bonding to existing risers, flow-lines, mooring lines, trees, and other structures in actual subsea environments. Developments include clamp prototypes, bonding techniques, long-term fatigue analysis, sensor calibration, and temperature compensation.

Fiber optic technology in subsea monitoring began over 20 years ago by migrating expertise from decommissioning of rocket motors. The first installations were on new installations of subsea pipelines, production risers, and drilling risers to measure strain and vibration for fatigue life monitoring. Of particular interest for these systems were detecting riser vortex induced vibration and strain throughout the touchdown zone. A prior limitation was that sensor installation was only performed top-side on new subsea equipment. This recent work demonstrates the capability to deploy on existing subsea equipment.

The novel contributions of this study are the developments that optimize the clamp design, bonding techniques, and factors that allow long-term service life. Button pull tests validate long term service life after the clamps are subjected to accelerated aging tests. Details on the subsea calibration also provide insight on the recent progress with post-installed sensors.

The purpose of reliable post-installed advanced sensors is not only to detect failures of subsea infrastructure but also to warn of signs of fatigue or hydrate formation that contribute to catastrophic failures. The calibration and testing mentioned in this paper are part of the Clear Gulf study, a collaboration formed in 2010 between the offshore energy industry and NASA. The study continues to make advances in highly sensitive monitoring systems that anticipate failures, catastrophic events, and flow assurance issues.

\section{NOMENCLATURE}

CFD Computational fluid dynamics

FBG Fiber Bragg Gratings

KIPS Units equal to $1000 \mathrm{lb}_{\mathrm{f}}$

ROV Remotely Operated Vehicle

TLP Tension Leg Platform

VIV Vortex Induced Vibration

$\alpha \quad$ Sensitivity factor for post-installed FBG sensors

$\beta \quad$ Baseline factor for post-installed FBG sensors

$\mu \epsilon_{F} \quad$ Raw micro-strain $(\mu m / m)$ from an FBG sensor

$\mu \epsilon_{S} \quad$ Calibrated micro-strain $(\mu \mathrm{m} / \mathrm{m})$ for an FBG sensor

\section{INTRODUCTION}

This paper relates significant advances for installation and calibration of non-penetrating sensors for monitoring of subsea structures as part of the Clear Gulf study. This work is a 
continuation of a prior study with test articles that are subjected to accelerated aging (1). The novel contributions of this study are new tensile strength measurements that quantify the effect of wet and dry bonding, innovative clamp designs, and methods for calibration of post-installed sensors. A major shortcoming of prior attempts at post-installed monitoring was the inadequate coupling of the sensor to the structure and this study provides methods to overcome this limitation. Advances in subsea sensing technology offers many options for highly accurate and distributed sensing solutions. Measurements for pressure, temperature, strain, hydrate formation, strain, vortex induced vibration (VIV), asphaltene buildup, wax deposition, and other quantities are well-established or under development and provide important insight for reservoir management, flow assurance, and in developing sophisticated predictive models. The modern sensors for newly installed systems combine to form a "central nervous system" for the production network that can sense and respond to abnormal or planned events. The system responds with changes to valves, pumps, pig deployment, methanol injection, pipe-in-pipe heating, ballast levels, and other actuators. A distributed sensor network can also provide input to an intelligent system that immediately responds to detected changes (2), checks for long-term fouling (3), schedules sequences of actions, performs regular maintenance, and likewise embeds years of experience by trained operators or model predictive algorithms into an automation solution (4-7). The combination of sensors, actuators, and intelligent system creates an Intelli-field where the lifecycle of the reservoir is actively monitored throughout exploration, drilling, completion, production, enhanced recovery phases, and well-abandonment (8-9).

While the Intelli-field concept is certainly possible for new installations, there remain two major obstacles for existing installations that are currently operating. The first limitation is that many sensor require penetration into the flow-line or subsea structure. Installation of penetrating sensors likely involves production shut-down, loss of structural integrity, and a change in containment strategy that was part of the original design. Installation of penetrating sensors to an existing field is often prohibitive for these reasons. Where penetrating sensors are not feasible, there also exist many types of non-penetrating sensors that can detect temperature, pressure, strain, hydrate formation, and other flow assurance concerns. The second major limitation is then how to couple the non-penetrating sensor to the structure in a subsea environment with divers or remotely operated vehicles (ROVs). For full lifecycle use, the bond that creates the sensor measurement coupling must maintain the required tensile strength to avoid loss of sensitivity. External clamp devices have also been designed to hold the sensor in place during the curing phase of the subsea adhesive and to protect the sensor. In some cases, it is desirable to use an external clamp without adhesive to facilitate replacement or maintenance of the sensor. This paper specifically investigates clamp design, coupling in simulated subsea conditions with accelerated aging tests, and calibration of the sensors once installed. Finite element modeling of the accelerated aging tests gives insight into the long-term service potential in areas of high strain or vibration. By enabling installation and long-term service life potential, additional sensors can be distributed along the flow-line without disrupting production on vast networks of currently operating systems.

\section{REMOTE MONITORING AND DIAGNOSTICS}

With the push to deepwater, arctic environments, and with longer subsea tie-backs, Intelli-field systems are becoming increasingly important to ensure performance of large investments. Several areas of interest for monitoring include the cement around the casing, the casing from the bottom of production casing to the well-head, the well-head, the flowline, the riser touchdown zone, and also with the top of the riser to evaluate the effectiveness of strakes designed to dampen VIV. Among some of the sensors considered are $\mathrm{pH}$, leak detection, pressure, temperature, heat flux, strain, vibration, material composition (i.e. liquid/gas states), hydrate formation and blockage development, asphaltene or paraffin detection, thermal insulation effectiveness, iceberg trenching, riser trenching, emulsions, erosion, internal corrosion, scales, fatigue, slugging and sloshing, and pig location. These can be analyzed with a combination of fiber-optic, ultrasonic, acoustic and other sensors. Using the sensors in the laboratory or with field data allows correlations to be developed or computational fluid dynamic (CFD) models to be validated to further improve the predictive capability of the Intelli-field system.

\section{FIBER-OPTIC MONITORING DEVELOPMENT}

The introduction of fiber optic sensors into the oil and gas industry stems from initial work in robotic sensing to provide tactile feedback within a robotic hand (9) as shown in Figure 1.

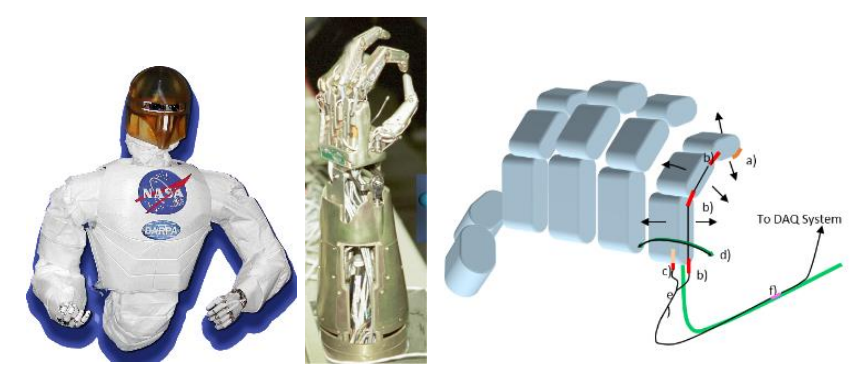

Figure 1. FIBER OPTIC FEEDBACK WITHIN THE ROBONAUT FINGER JOINTS AND TIPS (10).

This technology was also used to measure temperature and strain within a motor burning solid rocket propellant for the demilitarization of Intercontinental Ballistic Missiles (ICBMs). The use of fiber optic sensors was necessitated by the requirement for non-electrical monitoring in a high temperature and reactive environment. At the time, fiber optic sensing was an immature area and this success in rockets motors attracted interest from the oil and gas industry where sensing in remote and harsh environments is also desirable.

A first project in 1997 was the instrumentation of a 14 mile tie-back from the Troika wells in the Gulf of Mexico (11). The drilling risers of the vessels Ocean Clipper and Ocean 
Confidence (12) were instrumented with all fiber optic strain gauges to measure VIV. These 24" diameter drilling risers extended to a depth of $7500 \mathrm{ft}$. This work was done during drilling operations on the Neptune well in the Gulf of Mexico and is the first known study for real-time VIV measurements. This was a significant advance over the typical practice of datalogging and retrieval performed with accelerometers.

Another area of interest for strain and vibration was on the touchdown zone of several clusters of risers. These risers were instrumented on new flowlines connected to spar and semisubmersible platforms (13-14) as shown in Figure 2.

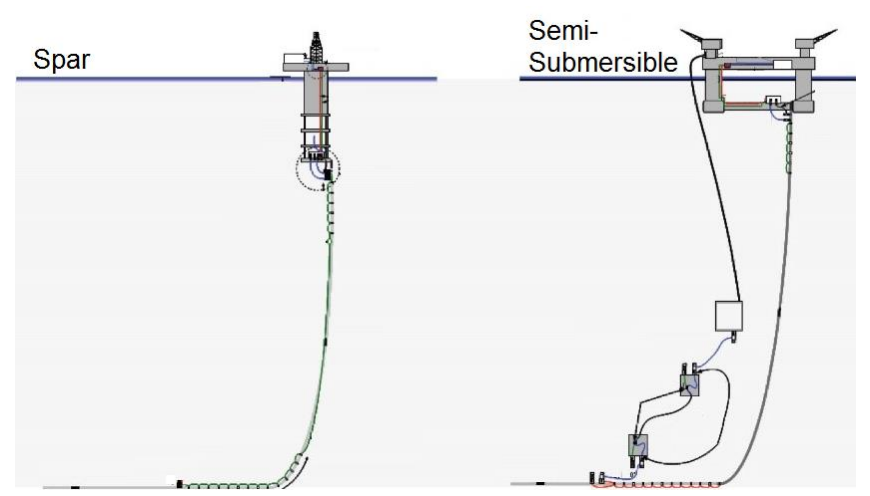

Figure 2. INSTRUMENTATION OF RISERS ON SPAR AND SEMI-SUBMERSIBLE PLATFORMS.

A major innovation came during project work on a tie-back at depths of approximately 7,000 feet (15). Several clam-shell sensor stations were installed on pipe before the initial pipe-lay for the new tie-back to an existing platform in the Gulf of Mexico. During the pipe-lay, the sensor station intended to monitor strain, temperature, and pressure at the well-head was damaged. With the well-head at nearly 7,000 feet and 56-miles from the platform, it was critical for operations to monitor pressure and temperature especially because the electrically operated sensors had failed shortly after startup. An ROV installable clamp was designed and installed to monitor temperature, pressure, and strain at the well-head. This installation was successful and after six years the system is still operational. Up to this period of technology development, only new installations could be attempted. This innovation demonstrated that post-installed monitoring solutions were also possible and would allow sensing of existing flowlines without penetration and without shutting down production.

Other recent developments in fiber optic monitoring include instrumentation of flexible risers, distributed strain and temperature sensing along pipelines (16-21), leak detection for LNG pipelines (22), and as communication networks for control applications. These recent developments are intended for new installations and not necessarily for installation on existing production systems.

The activities of this study to test subsea bonding, clamp design, and sensor calibration were sponsored by the Clear Gulf study and in support of an installation on two Tension Leg Platforms (TLPs) in West Africa (1). Loss of load cells readings for tendon tensions necessitated another approach at load sensing. During normal operations, the tendon tensions are not adjusted but are allowed to oscillate up and down by 40 to 90 kips $\left(1 \mathrm{kip}=1000 l b_{f}\right)$ due to tidal and wave action. However, when drilling equipment is loaded or other heavy lift operations are required, the tendon tensions are increased by removing ballast in anticipation of the additional weight on the platform. To stay within acceptable tendon tension ranges during the ballast and lift operations, a retrofitted tendon tension monitoring system was proposed using fiber optic sensing and diverinstallable clamps. Subscale test articles were fabricated after analysis with finite element analysis (FEA) during compression, tension, and bending tests. The FEA ensured that representative and uniform loads were applied to the test article and consistent with expected tendon tension load cycling. Aging tests were also conducted to ensure adequate potential for a long-term service life. Redundant sensors were installed on four of the eight tendons as shown in Figure 3 and have provided necessary information during an expansion of the platform production capacity to avoid over- or under-tensioning of the tendons.

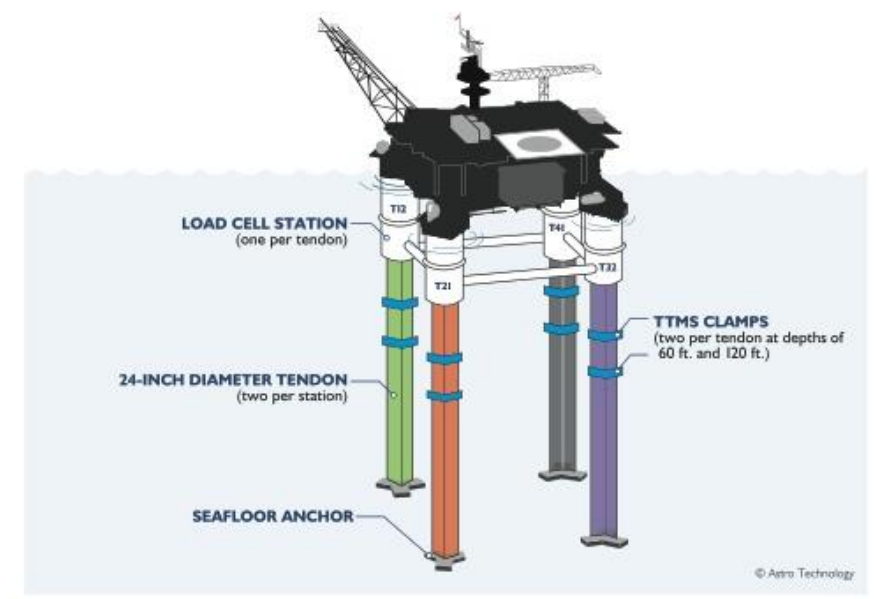

Figure 3. TENDON TENSION MONITORING SYSTEM.

With over a year of continuous monitoring, the coupling and aging tests have so far proved valid in suggesting long-term service life. Anticipated service life exceeds the life of the platform although individual sensor stations may need retuning and maintenance to perform well over an extended period.

\section{SENSOR COUPLING IN SUBSEA CONDITIONS}

Three test articles were used to determine the tensile strength of sensor bonding in subsea conditions. Full details of the testing in compression, tension, and in four point bending were given in a previous publication (1). The additional results in this section are the button pull tests that were used to evaluate the effectiveness of the sensor bonding after the accelerated aging tests, in wet and dry installation conditions, and also for samples that were not subjected to the cyclical aging tests. Figure 4 shows a diagram of the sensor clamp and the button pull locations for each of the sensing stations. Including samples at $90^{\circ}$ intervals is especially important with the four point bending 
test where some clamps were subjected to both compression and tension but on opposite sides of the clamp.

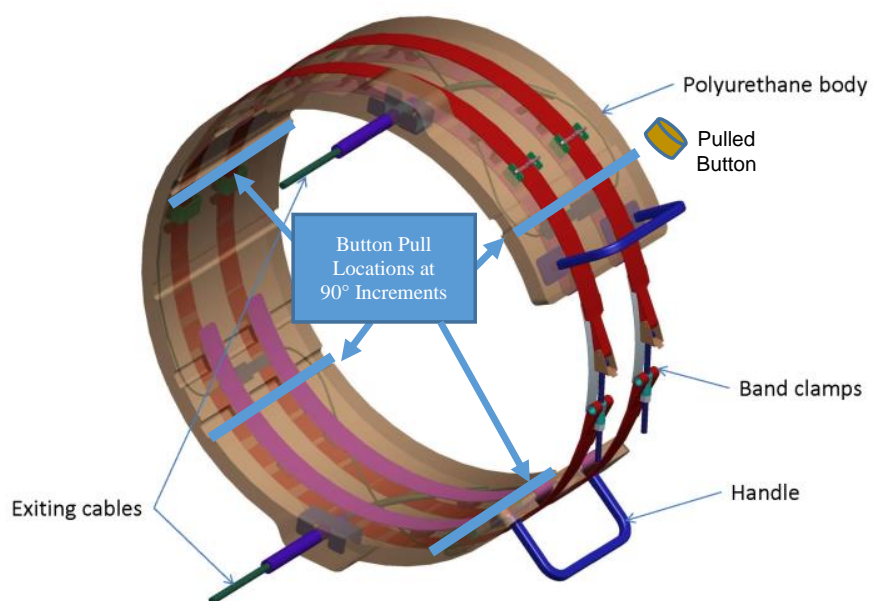

Figure 4. CLAMP DESIGN WITH BUTTON PULL TEST LOCATIONS.

Each of the tests includes the simulation of the test showing areas of strain or compression, a simplified diagram of the test, and a photo of the test article. Figure 5 shows the test article and simulation with the 14' length pipe used in the four point bending test. Clamps AA (wet) and BB (dry) were bonded after the testing as control samples to evaluate both the effect of wet bonding conditions and the effect of the aging tests. A full summary of the results is given in Annex A below with results for each of the individual clamps.

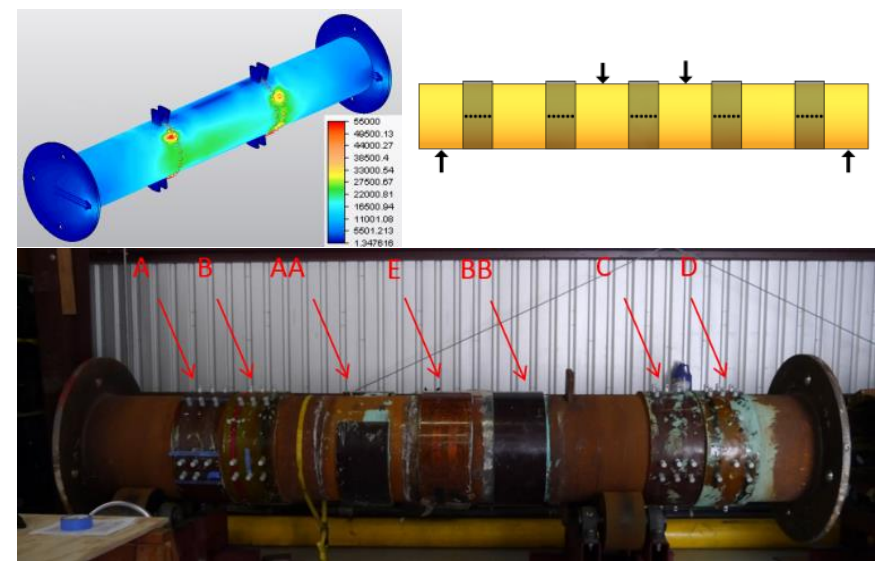

Figure 5. TEST ARTICLE AND CLAMP LOCATIONS FOR THE FOUR POINT BENDING TEST.

Figure 6 shows the test article and simulation with the 3' pipe used in the compression test and a separate test article used for the tension test. In this case, only a single sensor clamp was installed on each pipe segment (Clamps F and G). These test articles were subjected to compression or tension forces up to $70 \%$ of yield strength with 10 cycles of fast $(1 \% / \mathrm{min})$ and 10 cycles of slower $(0.1 \% / \mathrm{min})$ rate of change for each. The samples were also held at maximum tension or compression forces for a period of time before relaxation during each cycle.

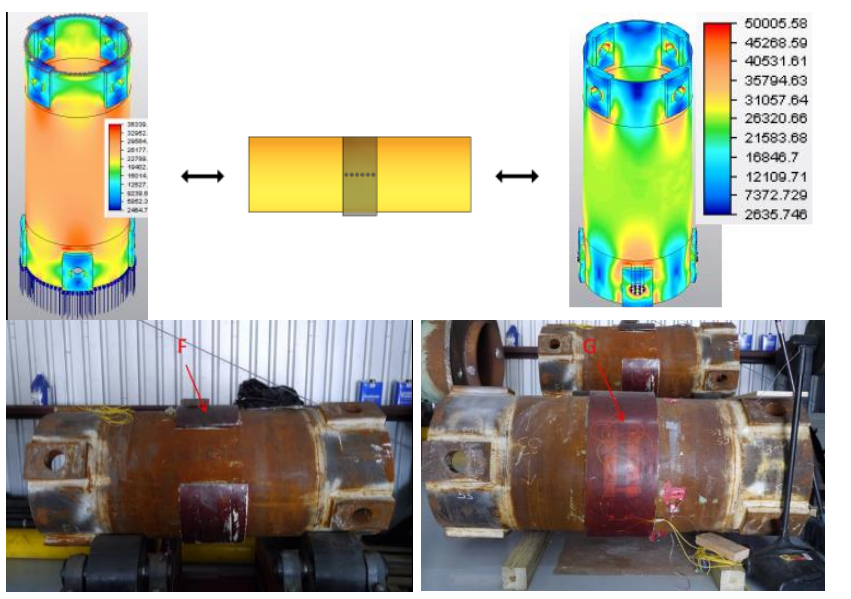

Figure 6. TEST ARTICLES AND CLAMP LOCATIONS FOR THE COMPRESSION AND TENSION TESTS.

For each of the button test samples, a small circular cut was made in the clamp material. Next, a tab was attached to the top of the circular piece as shown in Figure 7.
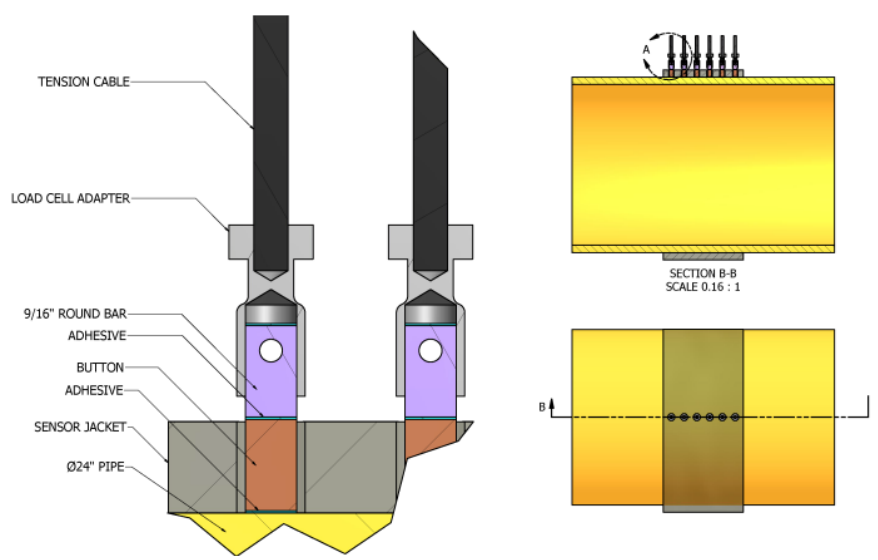

Figure 7. BUTTON PULL TEST TO MEASURE TENSILE STRENGTH.

The load for each test was measured with a load cell by pulling until there was an observed loss of resistive force where either the polyurethane or adhesive failed. Multiple samples were collected from each location to determine the average, standard deviation, minimum, and maximum for the tensile strength as shown in Table 1. 
Table 1. ADHESIVE STRENGTH BY LOCATION AND PREPARATION METHOD.

\begin{tabular}{|cccccl|}
\hline Clamp & $\begin{array}{c}\text { Avg } \\
\text { (psi) }\end{array}$ & $\begin{array}{c}\text { StDev } \\
\text { (psi) }\end{array}$ & $\begin{array}{c}\text { Min } \\
(\mathbf{p s i})\end{array}$ & $\begin{array}{c}\text { Max } \\
\text { (psi) }\end{array}$ & Description \\
\hline BB & 292.0 & 108.9 & 113.6 & 498.6 & Dry Bonded Control \\
\hline AA & 81.4 & 47.2 & 31.1 & 193.5 & Wet Bonded Control \\
\hline A & 94.0 & 30.4 & 45.0 & 155.8 & Four Point Bending (Left) \\
\hline B & 174.1 & 112.4 & 29.8 & 503.3 & Four Point Bending(Left) \\
\hline E & 91.1 & 46.9 & 49.5 & 150.8 & Four Point Bending (Center) \\
\hline C & 142.5 & 65.6 & 45.8 & 267.9 & Four Point Bending (Right) \\
\hline D & 136.3 & 73.6 & 57.5 & 358.7 & Four Point Bending (Right) \\
\hline F & 114.0 & 53.7 & 33.6 & 225.7 & Tension \\
\hline G & 105.3 & 59.8 & 29.7 & 268.8 & Compression \\
\hline
\end{tabular}

A summary of the tensile strength results is shown in Figure 8. All of the samples are displayed on a semi-log plot to lessen the visual effect of outliers. There are a number of interesting results from the study. A first observation, that was also expected, is that the dry bonded sample (BB) not subjected to aging tests had the highest median value of $236 \mathrm{psi}$ (or $292 \mathrm{psi}$ average) for tensile strength. Bonding in a dry environment allows the epoxy to better seal to the surface of the pipe possibly because of higher temperatures during the curing phase as well as lack of water to interfere with the bonding surfaces. Another somewhat surprising observation is that the aging tests did not decrease the tensile strength. Instead, all but one of the samples subjected to accelerated aging have higher median tensile strength than the wet-bonded control sample (AA). The AA clamp has a 66 psi median (or 81 psi average) tensile strength while the other samples subjected to strain up to $70 \%$ of failure have a 58-132 psi median (or 91-174 psi average) tensile strength. This apparent increase in the tensile strength has no immediately plausible explanation and may be due to some other unaccounted factor such as temperature of the water bath during clamp installation. The sensor clamps were installed in ambient conditions in Louisiana and Texas at slightly different temperatures and may have contributed to the bonding strength disparity. Another possible factor is the longer time for curing of the aged samples because the control samples were added after the accelerated aging tests. Additional tests are underway to quantify the effect of temperature and other critical to quality (CTQ) parameters for better isolation of these effects and to determine factors that lead to improved bonding. For example, will there be an effect on bonding strength when clamps are wet bonded at deep water temperatures of $0-4^{\circ} \mathrm{C}$ ? This and other questions will be answered through additional evaluation at NASA test facilities as part of the Clear Gulf study.

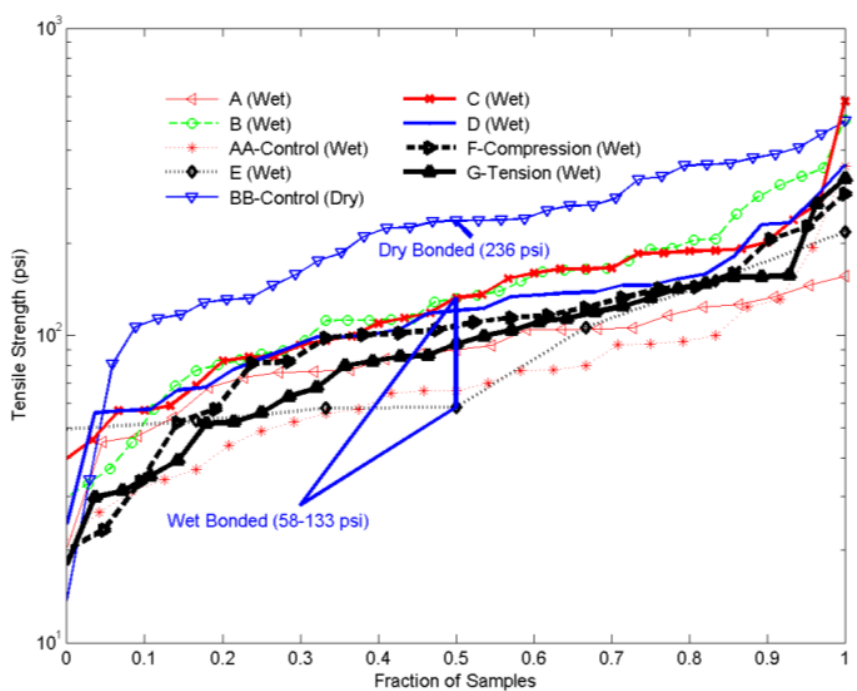

Figure 8. SUMMARY OF TENSILE STRENGTH RESULTS.

Other observations from these results are that there are high and low outliers and a nearly linear distribution on a log-scaled plot. Certain factors tend to shift the entire distribution up or down, but the slope of the log-scaled distribution remains constant regardless of the sample preparation method or accelerated aging.

The button pull tests further demonstrate that adequate bonding can be achieved in simulated subsea environments. The ability of the adhesive to maintain tensile strength even after accelerated aging shows the potential for long service life for post-installed sensors attached through adhesion methods.

\section{SENSOR CLAMP DESIGN}

In addition to adhesion studies, the clamp design has been modified to better support the FBG sensors, better disperse the bonding agent, and fit a variety of subsea structures such as risers, tendons, and flowlines. Various clamp prototypes have been designed in software and the molds have been printed with 3-D printing technology. The 3-D printed molds have enabled the creation of highly precise clamp designs such as the mold for an 8 " diameter flowline as shown in Figure 9. 


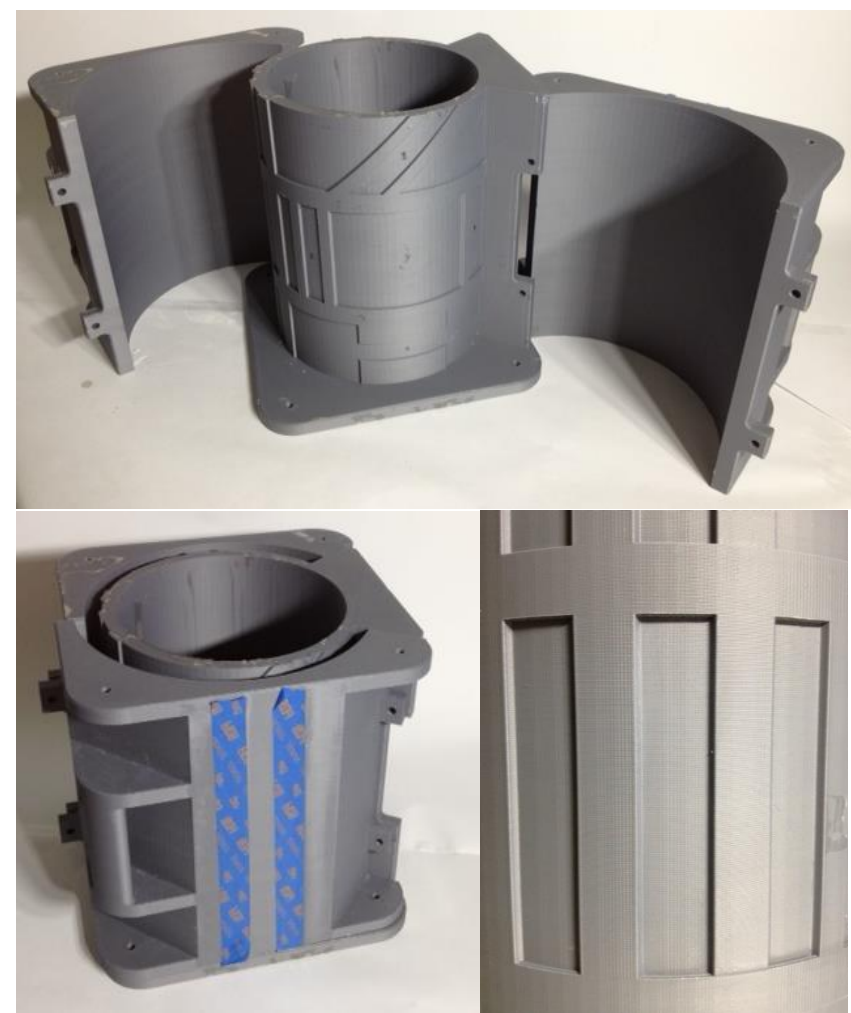

Figure 9. 3-D PRINTING OF A PROTOTYPE CLAMP MOLD FOR AN 8" FLOWLINE.

The 3-D printing technology will continue to expand the further customization of sensor stations for individual applications by improving precision, enabling development of complex prototypes, and reducing development time.

\section{SUBSEA SENSOR CALIBRATION}

Post-installed sensors require a unique calibration approach based on two issues. The first issue is that installation causes slight variations in the baseline strain values as the clamp is secured to the structure. Because of the strain induced during installation, the sensor baseline or zero-state cannot be calibrated before installation. This leads to an interesting challenge because the baseline value must be obtained from a known state. In most situations, an alternative measurement is either not available or not trusted for calibration of the sensors. A second issue for sensor calibration is in the sensitivity of the sensor because in most instances the sensor is unable to make direct contact with the item of interest. To make the fiber optic sensors robust to subsea installation, the delicate fiber optic sensors are protected in a sensing device designed to withstand the harsh environment and typical equipment handling found on offshore rigs. Therefore, changes in strain observed at the sensor may be less than actual strain changes on the structure. As long as the correct sensitivity is known, the conditioned sensor reading can report the actual changes, not just the changes at the sensor. The fiber optic is therefore calibrated with two parameters $\alpha$ and $\beta$ as shown in Equation 1 to relate measured strain $\left(\mu \epsilon_{F}\right)$ to calibrated strain $\left(\mu \epsilon_{S}\right)$.

$$
\mu \epsilon_{S}=\alpha \mu \epsilon_{F}+\beta
$$

Methods were developed for both accurate baseline and sensitivity calibration based on testing where 3' pipe samples were raised to $70 \%$ of failure in both compression and tension tests over multiple cycles. The correlation of Equation 1 is valid over repeated loading cycles and nearly to the point of inelastic deformation. The results of this calibration were then used to obtain approximate baseline values for the tendon tension monitoring system on the TLPs of West Africa. Once the clamps were installed, the load management system was used to approximate loads based on position and approximate weight of all objects on the platform, including loads of risers and buoyancy induced by tidal fluctuations. The sensitivity of the sensors was calibrated from the high and low peaks of the tidal fluctuations as shown in Figure 10. Time averaged values were used over a 5 minute horizon to eliminate the 4-8 second period for the wave action and natural platform harmonics.

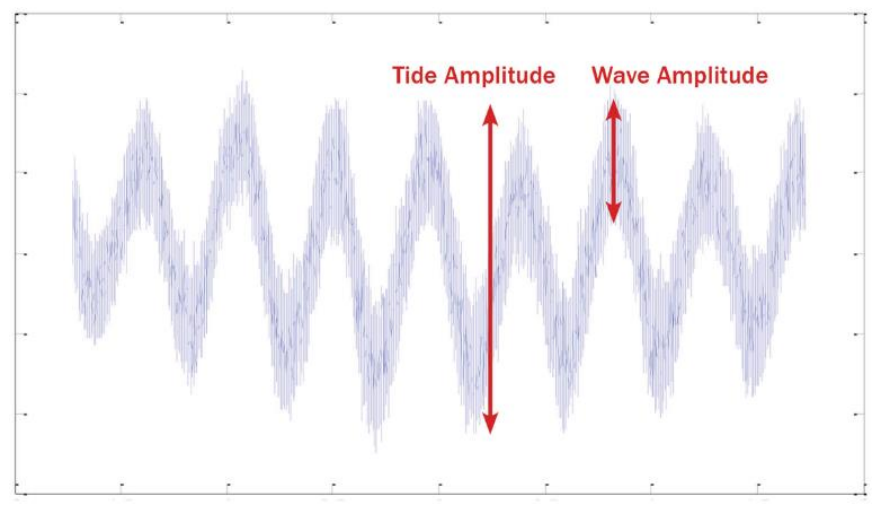

Figure 10: TIDE ACTION AMPLITUDES FOR CALIBRATION OF SENSOR SENSITIVITIES.

In the absence of known environmental disturbances, a movement of ballast on the platform would have been required to calibrate the range or parameter $\alpha$. Once the sensitivity value was set, an adjustment to $\beta$ was made to remove the installation induced strain and calibrate to a baseline value. This process was repeated over a week to verify load measurement accuracy.

Another challenge with this particular installation is that the first sensor station was installed at $60^{\prime}$ depth at the location of a thermocline. The depth of the thermocline moves above and below the sensor station, sometimes multiple times per day and has an abrupt $4^{\circ} \mathrm{C}$ change between the warmer and well-mixed waters above and the cooler deep water below as shown in Figure 11. 


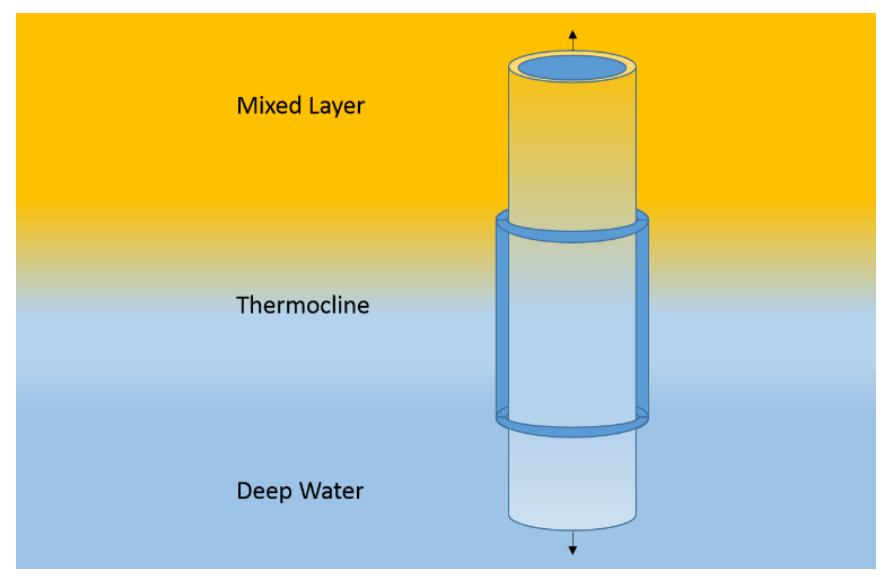

Figure 11. THERMOCLINE AT THE SENSOR CLAMP DEPTH LOCATED 60' BELOW THE SURFACE.

Without temperature compensation, this would cause a false apparent shift of several hundred kips. This temperature change effect was isolated and eliminated using a compensation technique. Because the temperature compensation sensor and the strain sensor were separated by approximately $3 \mathrm{~cm}$, the strain values were kept largely free of temperature effects, however, there was some observed shift. Future clamps on TLP tendons or risers will be placed away from known thermocline areas if possible.

\section{CONCLUSIONS}

This paper gives details on current progress on subsea bonding, clamp design, and calibration of advanced sensors for post-install applications. Significant progress has been made to ruggedize and develop fiber optics for use in monitoring subsea tie-backs from the well casing, at the well-head, along the flowline, and along critical parts of the riser. A discussion of the major obstacles to post-installed systems include types of nonpenetrating sensors and bonding techniques to create Intelli-field systems. These Intelli-field systems are a comprehensive monitoring solution to sense, predict, and respond immediately to anticipate issues before undesirable conditions arise. Technology development for monitoring of subsea structures is a task of the Clear Gulf study and a current phase is in testing adequate coupling methods for sensor to the existing subsea structures. The objectives of this study are to extend the service life of equipment, gain new understanding of flow properties and dynamics, prevent unplanned downtime, and detect problems earlier and more accurately. These objectives are becoming increasingly important as operations move to deepwater and arctic regions.

\section{ACKNOWLEDGMENTS}

The authors acknowledge the contributions of NASA Johnson Space Center in Houston in generating the button pull test results and the 3-D printing of the prototype clamps. Several leading oil and gas companies have provided technical and financial leadership in the Clear Gulf Joint Industry Project (JIP).
Founded in the fall of 2010, Clear Gulf JIP supports extensive testing and further development of advanced monitoring solutions, with critical input coming from experts at NASA as well as leaders within the industry. The project's technical steering committee includes representatives from participating companies. Participants are part of a high-profile effort to enhance safety and reduce environmental risk. The Clear Gulf steering committee will work with the Energy and Commerce Committee of the U.S. House of Representatives, the Bureau of Offshore Energy Management (BOEM), and the Bureau of Safety and Environmental Enforcement to ensure that systems support operators in meeting new offshore regulations.

\section{REFERENCES}

[1] Brower, D., Hedengren, J., Asgharzadeh Shishivan, R., and Brower, A., 2013. "Advanced Deepwater Monitoring System", In Ocean, Offshore \& Arctic Engineering OMAE, Nantes, France, no. 10920.

[2] Kelly, J., and Hedengren, J., 2013. "A steady-state detection (SSD) algorithm to detect non-stationary drifts in processes". Journal of Process Control, 23, 3, pp. 326-331, March 2013.

[3] Spivey, B., Hedengren, J., and Edgar, T., 2010. "Constrained nonlinear estimation for industrial process fouling". Industrial \& Engineering Chemistry Research, 49 (17), pp. 7824-7831, DOI: 10.1021/ie9018116.

[4] Hedengren, J., and Edgar, T., 2008. "Approximate nonlinear model predictive control with in situ adaptive tabulation". Computers and Chemical Engineering, 32, pp. 706-714.

[5] Hedengren, J., 2014. "Advanced Process Monitoring" in Optimization and Analytics in the Oil and Gas Industry, Eds. Kevin C. Furman, Jin-Hwa Song, Amr El-Bakry, Springer's International Series in Operations Research and Management Science.

[6] Powell, K., Hedengren, J., and Edgar, T. "Dynamic optimization of a solar thermal energy storage system over a 24hour period using weather forecasts", Proceedings of the American Control Conference (ACC), Washington, DC, pp. 2952-2957.

[7] Jacobsen, L., Spivey, B., and Hedengren, J., 2013. "Model predictive control with a rigorous model of a solid oxide fuel cell", Proceedings of the American Control Conference (ACC), Washington, DC, pp. 3747-3752.

[8] Brower, D., and Prescott, C., 2004. "Real time subsea monitoring and control smart field solutions", Subsea Rio, 3 (1), Rio de Janeiro, Brazil.

[9] Brower, D., Prescott, C., Zhang, J., Howerter, C., and Rafferty, D., 2005. "Real-time flow assurance monitoring with nonintrusive fiber optic technology", Proceedings of the Offshore Technology Conference, no. 17376.

[10] Lovchik, C., Diftler, M., 1999. "The Robonaut hand: a dexterous robot hand for space," Proceedings of IEEE International Conference on Robotics and Automation, Vol. 2, pp. 907-912.

[11] Brower, D. V., 2005. "Structural properties measurements in deepwater oil and gas fields using an advanced fiber-optic 
sensor monitoring system", Society for the Advancement of Material and Process Engineering (SAMPE).

[12] Brower, D., Abbassian, F., and Caballero, C., 2000. "Realtime Fatigue Monitoring of Deepwater Risers Using Fiber-Optic Sensors," Proceedings of ETCE/OMAE2000 Joint Conference: Energy for the New Millennium, New Orleans, LA. USA, February 14-17.

[13] Brower, D., 2003. "Real-time fatigue monitoring of deepwater drilling and oil production risers using fiber-optic sensors", Structural Health Monitoring Conference, Palo Alto, CA.

[14] Brower, D., Hedengren, J., Loegering, C., Brower, A., Witherow, K., and Winter, K., 2012. "Fiber optic monitoring of subsea equipment". In Ocean, Offshore \& Arctic Engineering OMAE, Rio de Janiero, Brazil, no. 84143.

[15] Hedengren, J., Brower, D., and Mojica, J., 2012. "Advanced process monitoring of flow assurance with fiber optics". In AIChE Spring Meeting.

[16] Glisic, B., and Inaudi, D., 2008. "Fibre optic methods for structural health monitoring", Wiley, West Sussex, England.

[17] Kersey, A., 2000. "Optical fiber sensors for permanent downwell monitoring applications in the oil and gas industry", IEICE Trans. Electron., E83-C(3), March, pp. 400-404.

[18] Eisler, B., Lanan, G., Niklès, M., and Zuckerman, L., 2008. "Distributed Fiber Optic Temperature Sensing System for Burried Subsea Arctic Pipelines", Proceedings of the Deep Offshore Technology International Conference \& Exhibition, DOT'08, Houston, Texas.

[19] Ravet, F., Rochat, E., and Niklès, M., 2013. "Challenges, requirements and advances for distributed fiber optic sensors in surf structures and subsea well monitoring", In Ocean, Offshore \& Arctic Engineering OMAE, Nantes, France, no. 10367.

[20] Decrin, M., Nebell, F., Naurois, H., and Parenteau, T., 2013. "Flow assurance modelling using an electrical trace heated pipein-pipe: from qualification to offshore testing", Proceedings of the Offshore Technology Conference, Houston, Texas, no. 24060.

[21] Kersey, A., Morey, W., and Berkoff, T., 1993. "Fiber-optic Bragg grating strain sensor with drift-compensated highresolution interferometric wavelength-shift detection," Opt. Lett. 18, pp. $72-74$.

[22] Prescott, C., Zhang, J., and Brower, D., 2005. "An ambient pressure insulated LNG pipeline for subsea environments", Proceedings of the Offshore Technology Conference, no. 17338. 


\section{ANNEX A}

\section{SUMMARY OF BUTTON PULL TEST DATA}

A summary of the button test results is given below for each of the pipe clamps. Clamps AA and BB are control samples. Clamp AA was installed wet and clamp BB was installed dry. All of the other clamps were installed under simulated subsea conditions in an underwater dive tank. Clamp sensors A-E were placed on a $14 \mathrm{ft}$ section of pipe and subjected to repeated bending tests. Clamps $\mathrm{F}$ and $\mathrm{G}$ were installed on $3 \mathrm{ft}$ pipe segments and subjected to tension and compression testing, respectively. highest average tensile strength is observed with the control sample (BB) at 292.0 psi. The lowest average tensile strength is observed with the other control sample (AA) at 81.4 psi affixed after the aging tests. The actual lowest required tensile strength has not yet been determined but will be the subject of further testing.

Table A1. SUMMARY OF A-E TENSILE STRENGTH DATA

\begin{tabular}{|c|c|c|c|c|c|c|c|c|}
\hline & Clamp A & Clamp B & Clamp AA & Clamp E & Clamp BB & Clamp C & Clamp D & Total \\
\hline Total Number of Test Conducted & 23 & 37 & 25 & 7 & 35 & 31 & 30 & 188 \\
\hline Number of Good Tests & 20 & 24 & 13 & 4 & 18 & 18 & 15 & 112 \\
\hline Number of Tab Break Tests & 2 & 11 & 11 & 1 & 17 & 12 & 13 & 67 \\
\hline Number of Bad Tests & 1 & 2 & 1 & 2 & 0 & 1 & 2 & 9 \\
\hline Min. Breaking Strength (psi) & 45.0 & 29.8 & 31.1 & 49.5 & 113.6 & 45.8 & 57.5 & \\
\hline Max. Breaking Strength (psi) & 155.8 & 503.3 & 193.5 & 150.8 & 498.6 & 267.9 & 358.7 & \\
\hline Average Breaking Strength (psi) & 94.0 & 174.1 & 81.4 & 91.1 & 292.0 & 142.5 & 136.3 & \\
\hline $\begin{array}{r}\text { Breaking Strength Standard Deviation } \\
\text { (psi) }\end{array}$ & 30.4 & 112.4 & 47.2 & 46.9 & 108.9 & 65.6 & 73.6 & \\
\hline Predominate Adhesive Failure Mode & Poly Surface & Steel Surface & Steel Surface & Poly Surface & Mixed & Mixed & Steel Surface & \\
\hline
\end{tabular}

Table A2. SUMMARY OF F-G TENSILE STRENGTH DATA

\begin{tabular}{|c|c|c|c|}
\hline & Clamp F & Clamp G & Total \\
\hline Total Number of Test Conducted & 22 & 29 & 51 \\
\hline Number of Good Tests & 15 & 15 & 30 \\
\hline Number of Tab Break Tests & 2 & 5 & 7 \\
\hline Number of Bad Tests & 5 & 9 & 14 \\
\hline Min. Breaking Strength (psi) & 33.6 & 29.7 & \\
\hline Max. Breaking Strength (psi) & 225.7 & 268.8 & \\
\hline Average Breaking Strength (psi) & 114.0 & 105.3 & \\
\hline $\begin{array}{r}\text { Breaking Strength Standard Deviation } \\
(\mathrm{psi})\end{array}$ & 53.7 & 59.8 & \\
\hline Predominate Adhesive Failure Mode & Steel Surface & Poly Surface & \\
\hline
\end{tabular}

The total number of pull button tests conducted was 239 with a total of 142 good results. Sources of failed tests included tab breaks that may indicate the tensile strength was very high due to incomplete button cutting or a very strong bond. This is evident with clamp BB that had the highest average tensile strength and the highest number of tab breaks. There were also a number of bad tests with various causes ranging from the button pull mechanism to the button preparation. For each of the clamp results, a minimum, maximum, average, and standard deviation of the breaking strength are reported in units of psi. A predominate adhesive failure mode is also reported as either the polyurethane surface, steel surface, or mixed failure modes. This indicates whether the failure was due to the bonding (steel surface) or the strength of the polyurethane (poly surface). Overall, the test results show excellent bonding even with simulated subsea adhesion and after simulated aging tests. The 